\title{
MATHEMATICAL ASSOCIATION
}

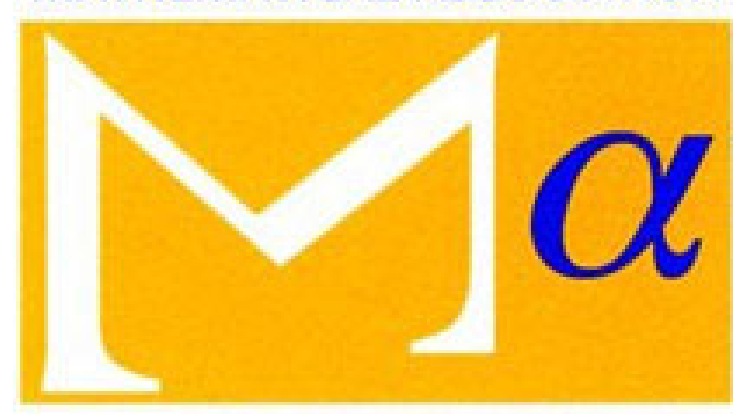

supporting mathematics in education

596. Remarks on Note 554: Area of a Triangle in Terms of the Coordinates of Its Angular Points

Author(s): F. G. Brown

Source: The Mathematical Gazette, Vol. 10, No. 155 (Dec., 1921), p. 376

Published by: The Mathematical Association

Stable URL: http://www.jstor.org/stable/3604634

Accessed: 17/01/2015 13:30

Your use of the JSTOR archive indicates your acceptance of the Terms \& Conditions of Use, available at http://www.jstor.org/page/info/about/policies/terms.jsp

JSTOR is a not-for-profit service that helps scholars, researchers, and students discover, use, and build upon a wide range of content in a trusted digital archive. We use information technology and tools to increase productivity and facilitate new forms of scholarship. For more information about JSTOR, please contact support @ jstor.org. 
595. [ $\mathrm{L}^{1} .4$. a.] Proof that the Tangent to a Conic is equally inclined to the Focal Vectors.

The following geometrical proof is extremely simple.

1. Let $F$ and $G$ be two points on opposite sides of a line $l$, which meets $F G$ at $M$. Then, if $P$ and $Q$ are two points on $l$ such that $F P+P G=F Q+Q G$, $P$ and $Q$ are on opposite sides of $M$.

Let $F^{\prime}$ be the image of $G$ in $l$; it follows that, if $F$ and $F^{\prime}$ are two points on the same side of $l$, and $P$ and $Q$ are two points on $l$ such that

$$
F P+P F^{\prime}=F Q+Q F^{\prime},
$$

there is a point $M$ on $l$ between $P$ and $Q$ such that $M F$ and $M F^{\prime}$ are equally inclined to $P Q$. The conditions hold if $P$ and $Q$ are any two points on an ellipse (both on the same side of the major axis), $F$ and $F^{\prime}$ being the foci. Making $Q$ tend towards $P$, we get the theorem for an ellipse.

2. The proof for a hyperbola is almost identical. Take $P$ and $Q$ on the same branch and on the same side of the transverse axis. The lemma required is this: If $F$ and $G$ are on the same side of $l$, and $P$ and $Q$ on $l$ are such that $F P-P G=F Q-Q G, P$ and $Q$ are on opposite sides of the intersection $M$ of $l$ and $F G$.

M. F. Egan.

35 Lower Leeson Street, Dublin.

596. [K'1. 1. d.] Remarks on Note 554: Area of a Triangle in Terms of the Coordinates of its Angular Points.

It seems possible to meet Austral's wishes even more determinantly.

Let $A(0,0), B\left(x_{1}, y_{1}\right), C\left(x_{2}, y_{2}\right)$ be the angular points of the triangle.

In polars, $B$ is $\left(r_{1}, \theta_{1}\right), C$ is $\left(r_{2}, \theta_{2}\right)$.

The area $=\frac{1}{2} r_{1} r_{2} \sin \left(\theta_{2}-\theta_{1}\right)$

$$
\begin{aligned}
& =\frac{1}{2} r_{1} r_{2}\left(\sin \theta_{2} \cos \theta_{1}-\cos \theta_{2} \sin \theta_{1}\right) \\
& =\frac{1}{2} r_{1} r_{2}\left|\begin{array}{ll}
\sin \theta_{2} & \sin \theta_{1} \\
\cos \theta_{2} & \cos \theta_{1}
\end{array}\right|, \quad \text { by the fundamental definition } \\
& =\frac{1}{2}\left|\begin{array}{ll}
r_{2} \sin \theta_{2} & r_{1} \sin \theta_{1} \\
r_{2} \cos \theta_{2} & r_{1} \cos \theta_{1}
\end{array}\right|, \text { by the common-factor rule, } \\
& =\frac{1}{2}\left|\begin{array}{ll}
y_{2} & y_{1} \\
x_{2} & x_{1}
\end{array}\right| \\
& =\frac{1}{2}\left|\begin{array}{ll}
x_{1} & y_{1} \\
x_{2} & y_{2}
\end{array}\right| .
\end{aligned}
$$

With angular points $A\left(x_{3}, y_{3}\right), B\left(x_{1}, y_{1}\right), C\left(x_{2}, y_{2}\right), A$ being $\left(r_{3}, \theta_{3}\right)$,

the area $=O B C+O C A+O A B$, in all cases,

$$
\begin{aligned}
& =\frac{1}{2}\left|\begin{array}{ll}
x_{1} & y_{1} \\
x_{2} & y_{2}
\end{array}\right|+\frac{1}{2}\left|\begin{array}{ll}
x_{2} & y_{2} \\
x_{3} & y_{3}
\end{array}\right|+\frac{1}{2}\left|\begin{array}{ll}
x_{3} & y_{3} \\
x_{1} & y_{1}
\end{array}\right| \\
& =\frac{1}{2}\left|\begin{array}{lll}
x_{1} & y_{1} & 1 \\
x_{2} & y_{2} & 1 \\
x_{3} & y_{3} & 1
\end{array}\right| .
\end{aligned}
$$

On the question of sign, follow the usual convention,--positive area is on your left as you traverse its boundary. "Austral's " method uses the absolute value of the perpendicular from a point to a line, and with numerical values his result may be positive or negative. The above method avoids this ambiguity. It also helps to prevent the pupil from concluding that you never get determinants except by elimination when using equations. One gets the same sort of fixed idea in connection with s.H.M. and the circle.

Sydney.

F. G. Brown. 